\title{
Biofilm disrupting technology for orthopedic implants: what's on the horizon?
}

\section{Alexander Connaughton ${ }^{1}$, Abby Childs ${ }^{2}$, Stefan Dylewski ${ }^{1}$ and Vani J. Sabesan ${ }^{2 *}$}

${ }^{1}$ Michigan State University College of Human Medicine, Grand Rapids, MI, USA

${ }^{2}$ Western Michigan University Homer Stryker MD School of Medicine, Kalamazoo, MI, USA

\section{Edited by: \\ Haider Abdul-Lateef Mousa, \\ University of Basrah, Iraq}

\section{Reviewed by:}

Mohammad Mohseni Sajadi, Institute of Human Virology at the University of Maryland School of Medicine, USA

Peter F. Choong, University of

Melbourne, Australia

*Correspondence:

Vani J. Sabesan, 1000 Oakland Drive Kalamazoo, MI, USA

e-mail:sabes001@gmail.com
The use of orthopedic implants in joints has revolutionized the treatment of patients with many debilitating chronic musculoskeletal diseases such as osteoarthritis. However, the introduction of foreign material into the human body predisposes the body to infection. The treatment of these infections has become very complicated since the orthopedic implants serve as a surface for multiple species of bacteria to grow at a time into a resistant biofilm layer. This biofilm layer serves as a protectant for the bacterial colonies on the implant making them more resistant and difficult to eradicate when using standard antibiotic treatment. In some cases, the use of antibiotics alone has even made the bacteria more resistant to treatment. Thus, there has been surge in the creation of non-antibiotic anti-biofilm agents to help disrupt the biofilms on the orthopedic implants to help eliminate the infections. In this study, we discuss infections of orthopedic implants in the shoulder then we review the main categories of anti-biofilm agents that have been used for the treatment of infections on orthopedic implants. Then, we introduce some of the newer biofilm disrupting technology that has been studied in the past few years that may advance the treatment options for orthopedic implants in the future.

Keywords: biofilms, orthopedics, joint replacements, novel technology, periprosthetic fractures, infectious disease medicine
Implants have become an indispensable part of orthopedic medicine. The use of orthopedic implants has revolutionized the treatment of patients with debilitating diseases like osteoarthritis and bone fractures. However, the compromise of the skin barrier during surgical procedures and the introduction of foreign material during joint replacement may predispose the body to infection, including biofilm creating bacteria.

A biofilm is an assemblage of surface-associated microbial cells that is enclosed in an extracellular polymeric substance (EPS) matrix (1). Biofilms are enhanced by the ability of bacteria to attach to an orthopedic implant through their surface structures such as pili, fimbriae, flagella, and glycocalyx (2). Additionally, adherence of microorganisms to the surface of the implant may involve non-specific factors like surface tension, hydrophobicity, and electrostatic forces (1). In general, any surface is susceptible to biofilm growth, but rougher and more hydrophobic surfaces will accumulate biofilms more rapidly (3). These bacterial biofilms can grow to reach thicknesses of $100 \mathrm{~mm}$ (4). The depletion of nutrients that can easily occur at the implant surface results in a slow growing stationary state that can render the biofilm up to 1000 times more resistant to most antimicrobial agents when compared to the single bacteria cell (4). Eradicating these complicated slow growing biofilms with antibiotic therapy alone becomes extremely difficult. Prosthetic joint biofilms can be mono- or polymicrobial and are frequently caused by Staphylococcus aureus, coagulasenegative Staphylococci, beta-hemolytic Streptococci, and aerobic Gram negative rods (including Pseudomonas aeruginosa) (5) Moreover, the timeline of the biofilm formation has proven to be critical to its susceptibility to antibiotics (6). In other words, within the first week of formation, a biofilm might be susceptible to tobramycin and piperacillin and subsequently become resistant (6). Treatment with only antibiotics can increase the resistance of these infections and there have even been cases where they have stimulated the growth of the biofilms $(7,8)$.

The development of these complicated infections after orthopedic implant surgery is a major problem. There are about one million joint replacements, hip, knee, and shoulder $(9,10)$, performed each year in the United States, which is expected to exceed four million by $2030(11,12)$. Infection rates for hip, knee, and shoulder arthroplasty at most centers are reported to be $<2 \%$, with most of these occurring in the first 2 years post-op $(4,8,11$, 13). One and two-stage revision can serve as definitive treatment and success rates have been documented in case-series to be 80 and 90\%, respectively (14-17). Additionally, aggressive debridement and retention of the implant is an option in select cases of early-onset infection (30 days after implant) with no evidence of loosening or sinus tract formation (18). This strategy in earlyonset infection may be curative in combination with long-term antibiotics in up to $71 \%$ of cases (19-21). Finally, resection without reimplantation is a last resort (16). However, the cost and morbidity of periprosthetic joint infections and revision joint arthroplasty can be exorbitant (22). Conservative estimates suggest that each prosthetic joint infection may cost $\$ 50,000$ or more (23), and the total economic burden of these prosthetic joint infections will only continue to increase with the number of total joint arthroplasties performed every year $(13,22)$. That is why it is imperative that 
we continue to pursue other methods besides antibiotics to help prevent and treat biofilm-forming infections. We will review the different types of technology that have been developed to deter biofilm formation and introduce some of the newer interventions being researched to combat these infections.

Modification of the orthopedic implants is one of the first aspects looked at in preventing these infections. The type of alloy used in implants has been the focus of many research studies. When testing the ability of some of the more common bacteria in implant infections such as the Staphylococcus spp., it was found that the bacteria had decreased ability to adhere and create a biofilm layer on titanium than stainless steel or polymethylmethacrylate (24). This can be explained by the ability of titanium to keep the bacteria dispersed on the implant surface making the bacteria more susceptible to antibiotics (25). This antimicrobial effect is one reason why titanium alloy has become one of the more popular alloy used in orthopedic implants. A recent study looked at innovations using titanium alloy investigating vanadium free titanium alloys. They found this specialized alloy had decreased bacterial adherence and biofilm formation than titanium that contains vanadium (26).

The field of anti-biofilm agents has been increasing dramatically and there is an exhaustive list of agents in each category of this field as described in Campoccia et al. (27). Agents that have bacteria repelling and anti-adhesive surfaces target the factors that enhance adhesion of the bacteria to the orthopedic implant that are ubiquitous to the common infecting bacteria (27). These antibiofilm agents utilize hydrophilic, highly hydrated, and anionic surfaces that are typically most difficult for bacteria to adhere to (27). Polyethylene oxide is an example of this category that can be applied to a synthetic surface such as an orthopedic implant to prevent bacterial attachment and biofilm development (28). While most anti-biofilm surface repelling agents use hydrophilic properties, there is also a recent example of an agent that uses a hydrophobic polycationic surface on titanium and stainless steel implants. These were found to inhibit biofilm formation and also enhance bone healing in an infectious environment (29).

Another category of anti-biofilm agents are intrinsically bioactive materials that are non-antibiotic compounds with innate antibacterial properties in their structure. Examples in this category are metals such as silver and copper. The antibacterial properties of the metals come from their corrosive properties that result in ion release that can disrupt essential processes of the bacteria such as those in the respiratory chain (27). These metals can be integrated onto the surface of an orthopedic implant to prevent adhesion of the bacteria.

There are many examples of bioactive antibacterial coatings that are placed on top of an implant surface that have active antibacterial properties. One example of this is when the implant surface is cross-linked with a bioactive molecule such as human b-defensin-3. Recent studies on the antimicrobial peptide human b-defensin-3 show that it has the capacity to reduce the number of bacterial colonies that accumulate on titanium surfaces and can be effective against resistant organisms such as methicillinresistant Staphylococcus epidermidis (MRSE) and methicillinresistant Staphylococcus aureus (MRSA) (30, 31). Another type of bioactive antibacterial coating releases nitric oxide that can combine with superoxide to produce peroxynitrite, which has very cytotoxic actions against bacteria (27). Polymer coatingscontaining diazeniumdiolates are an example of a nitric-oxide releasing coating $(27,32)$. Along the same line are reactive oxygen species-releasing coatings such as polycaprolactone incorporating calcium peroxide (27). Studies have shown that bursts of calcium peroxide can be bactericidal while only having short term toxic effects to surrounding host tissues (33). There are also photoactivated bioactive biomaterials that can be activated at certain UV wavelength to exhibit their bactericidal effects such as the anatase $\mathrm{TiO}_{2}$, which is activated at the $385 \mathrm{~nm}$ UV wavelength (27).

Another category is nanostructured biomaterials that contain compounds such as silver or chitosan that have antibacterial properties (27). The nanostructures can also be used to alter the surface functionality (solubility, surface charge, and other properties) of the implant making it more difficult for bacteria to attach $(27,34)$.

Research is being focused on the use of vaccines against bacteria that commonly infect implants. These vaccines contain polysaccharide or protein from the bacterial surface. When they are administered, the body develops immunoglobins against these bacterial proteins or polysaccharides to prevent the biofilm formation (34). Most attempts at developing a vaccine against Staphylococcus aureus have been largely unsuccessful due to the adaptability and phenotypic variation exhibited by this bacteria (35). One example that showed promise was the StaphVAX against Staphylococcus aureus capsular polysaccharides. StaphVAX successfully made it to phase III clinical trials, but was withdrawn when the vaccine's effectiveness in producing the immunoglobins against the bacteria decreased to $<30 \%$ in the year (36). A recently developed quadrivalent vaccine against Staphylococcus aureus (targeting glucosaminidase, an $\mathrm{ABC}$ transporter lipoprotein, a conserved hypothetical protein, and a conserved lipoprotein) was able to clear $87.5 \%$ of the bacterial biofilm infections in combination with antibiotics compared to $22 \%$ in those just given with the vaccine (37). This shows the importance of combining vaccine and antibiotic treatment with this therapy if it becomes successful clinically in the future.

The use of bacteriophages, which are viruses that infect and destroy bacteria, have recently been explored for their effects to remove biofilms in orthopedic implants. One study found that bacteriophages enhanced the effects of antibiotics in eliminating orthopedic implant infections of MRSA and Pseudomonas aeruginosa in rat models (38).

Bioactive enzymes lyse certain elements of the biofilm aggregating on the orthopedic implant resulting in the destruction of the biofilm. For example, dispersin B, which lyses polymers or Proteinase $\mathrm{K}$, which lyses proteins of the biofilm structure both of which make the bacteria more susceptible to antibiotic treatment (27). A number of cytotoxic agents have also been found to be successful in removing biofilms from implant surfaces. In a recent review, the most successful cytotoxic agent found to eliminate biofilms on titanium surfaces was citric acid (39). While there is limited literature on these agents, they show promise and more studies are needed to fully understand their efficacy.

Another new field being researched is the use of electrical stimulation on orthopedic implant surfaces. Studies have shown that when an electrical current was applied to a stainless steel implant 
infected with Staphylococcus aureus and Staphylococcus epidermis, the current was able to enhance detachment of the biofilm (40-42). One of these studies tested the use of an electric current in vivo with rabbit models that had an external power source that was attached to an infected stainless steel implants that provided a current. They found this model to be successful in reducing the biofilm load (41). Applying an electrical current to infected implants in combination with antibiotic therapy could be favorable treatment algorithm in the future so that patients could avoid having to go through major single-stage revision or two-stage reimplantation procedures.

Another potential innovation applied pulsed electromagnetic fields to stainless steel pegs infected with biofilms of Staphylococcus epidermis in combination with antibiotics. This study reported a $50 \%$ decrease in the minimum biofilm inhibitory concentration needed for gentamicin; however, this effect was not seen with vancomycin (43).

A new surge in research has been in the use of laser-generated shockwaves, which use mechanical energy to break up biofilms (35). One study found that around 97.9\% of Pseudomonas aeruginosa biofilms on nitinol stents could be removed with just 4-10 s of applying the laser (44). Laser-generated shockwaves were able to break up the biofilm layer into bacteria in its single-celled planktonic form that can be more easily treated with antibiotics (44).

We can no longer rely solely on antibiotics and surgery to treat these infections because of the increased patient costs and morbidity. In addition, the current treatment algorithms are becoming increasingly less effective with more virulent organisms and bacterial resistance. The application of various technologies and different disciplines can advance the field of biofilm disrupting technology. Innovative biofilm-disrupting-treatments are at the forefront of medical research as scientists continue to look for new technology to combat the complicated bacteria that infect implants.

\section{REFERENCES}

1. Donlan RM. Biofilms: microbial life on surfaces. Emerg Infect Dis (2002) 8(9):881-90. doi:10.3201/eid0809.020063

2. Renner LD, Weibel DB. Physicochemical regulation of biofilm formation. MRS Bull (2011) 36(5):347-55. doi:10.1557/mrs.2011.65

3. Ribeiro M, Monteiro FJ, Ferraz MP. Infection of orthopedic implants with emphasis on bacterial adhesion process and techniques used in studying bacterial-material interactions. Biomatter (2012) 2(4):176-94. doi:10.4161/ biom. 22905

4. Zoubos AB, Galanakos SP, Soucacos PN. Orthopedics and biofilm - what do we know? A review. Med Sci Monit (2012) 18(6):RA89-96. doi:10.12659/MSM. 882893

5. Berbari EF, Hanssen AD, Duffy MC, Steckelberg JM, Ilstrup DM, Harmsen WS, et al. Risk factors for prosthetic joint infection: case-control study. Clin Infect Dis (1998) 27(5):1247-54. doi:10.1086/514991

6. Anwar H, Strap JL, Chen K, Costerton JW. Dynamic interactions of biofilms of mucoid Pseudomonas aeruginosa with tobramycin and piperacillin. Antimicrob Agents Chemother (1992) 36(6):1208-14. doi:10.1128/AAC.36.6.1208

7. Campoccia D, Montanaro L, Speziale P, Arciola CR. Antibiotic-loaded biomaterials and the risks for the spread of antibiotic resistance following their prophylactic and therapeutic clinical use. Biomaterials (2010) 31(25):6363-77. doi:10.1016/j.biomaterials.2010.05.005

8. Cargill JS, Upton M. Low concentrations of vancomycin stimulate biofilm formation in some clinical isolates of Staphylococcus epidermidis. J Clin Pathol (2009) 62(12):1112-6. doi:10.1136/jcp.2009.069021

9. Gilson M, Gossec L, Mariette X, Gherissi D, Guyot MH, Berthelot JM, et al. NIH consensus conference: total hip replacement. NIH consensus development panel on total hip replacement. JAMA (1995) 273(24):1950-6. doi:10.1001/jama.273. 24.1950
10. Kurtz S, Ong K, Lau E, Mowat F, Halpern M. Projections of primary and revision hip and knee arthroplasty in the United States from 2005 to 2030. J Bone Joint Surg Am (2007) 89(4):780-5. doi:10.2106/JBJS.F.00222

11. Bohsali KI, Wirth MA, Rockwood CA. Complications of total shoulder arthroplasty. J Bone Joint Surg Am (2006) 88(10):2279-92. doi:10.2106/JBJS.F.00125

12. Lee B. Joint Replacement in U.S. Exceed 1 Million a Year. Pittsburgh, PA: Scripps Howard News Service (2013). Available from: http://www.post-gazette.com/ news/health/2013/03/04/Joit-replacements-in-U-S-exceed-1-million-a-year/ stories/201303040218

13. Piper KE, Jacobson MJ, Cofield RH, Sperling JW, Sanchez-Sotelo J, Osmon DR, et al. Microbiologic diagnosis of prosthetic shoulder infection by use of implant sonication. J Clin Microbiol (2009) 47(6):1878-84. doi:10.1128/ JCM.01686-08

14. Biring GS, Kostamo T, Garbuz DS, Masri BA, Duncan CP. Two-stage revision arthroplasty of the hip for infection using an interim articulated Prostalac hip spacer: a 10- to 15-year follow-up study. J Bone Joint Surg Br (2009) 91(11):1431-7. doi:10.1302/0301-620X.91B11.22026

15. Brandt CM, Duffy MC, Berbari EF, Hanssen AD, Steckelberg JM, Osmon DR. Staphylococcus aureus prosthetic joint infection treated with prosthesis removal and delayed reimplantation arthroplasty. Mayo Clin Proc (1999) 74(6):553-8. doi:10.4065/74.6.553

16. Sia IG, Berbari EF, Karchmer AW. Prosthetic joint infections. Infect Dis Clin North Am (2005) 19(4):885-914. doi:10.1016/j.idc.2005.07.010

17. Zeller V, Lhotellier L, Marmor S, Leclerc P, Krain A, Graff W, et al. Onestage exchange arthroplasty for chronic periprosthetic hip infection: results of a large prospective cohort study. J Bone Joint Surg Am (2014) 96(1):el. doi:10.2106/JBJS.L.01451

18. Osmon DR, Berbari EF, Berendt AR, Lew D, Zimmerli W, Steckelberg JM, et al. Diagnosis and management of prosthetic joint infection: clinical practice guidelines by the Infectious Diseases Society of America. Clin Infect Dis (2013) 56(1):el-25. doi:10.1093/cid/cis803

19. Byren I, Bejon P, Atkins BL, Angus B, Masters S, McLardy-Smith P, et al. One hundred and twelve infected arthroplasties treated with 'DAIR' (debridement, antibiotics and implant retention): antibiotic duration and outcome. J Antimicrob Chemother (2009) 63(6):1264-71. doi:10.1093/jac/dkp107

20. El HelouOC, Berbari EF, Lahr BD, Eckel-Passow JE, Razonable RR, Sia IG, et al. Efficacy and safety of rifampin containing regimen for staphylococcal prosthetic joint infections treated with debridement and retention. Eur J Clin Microbiol Infect Dis (2010) 29(8):961-7. doi:10.1007/s10096-010-0952-9

21. Zimmerli W, Widmer AF, Blatter M, Frei R, Ochsner PE. Role of rifampin for treatment of orthopedic implant-related staphylococcal infections: a randomized controlled trial. Foreign-Body Infection (FBI) Study Group. JAMA (1998) 279(19):1537-41. doi:10.1001/jama.279.19.1537

22. Poultsides LA, Liaropoulos LL, Malizos KN. The socioeconomic impact of musculoskeletal infections. J Bone Joint Surg Am (2010) 92(11):e13. doi:10.2106/ JBJS.I.01131

23. Sculco TP. The economic impact of infected joint arthroplasty. Orthopedics (1995) 18(9):871-3.

24. Gad GFM, Aziz AAA, Ibrahem RA. In-vitro adhesion of Staphylococcus spp. to certain orthopedic biomaterials and expression of adhesion genes. JAppl Pharm Sci (2012) 02(6):145-9. doi:10.7324/JAPS.2012.2634

25. Lauderdale KJ, Malone CL, Boles BR, Morcuende J, Horswill AR. Biofilm dispersal of community-associated methicillin-resistant Staphylococcus aureus on orthopedic implant material. J Orthop Res (2010) 28(1):55-61. doi:10.1002/jor. 20943

26. Walkowiak-Przybyło M, Klimek L, Okrój W, Jakubowski W, Chwiłka M, Czajka A, et al. Adhesion, activation, and aggregation of blood platelets and biofilm formation on the surfaces of titanium alloys Ti6Al4V and Ti6Al7Nb. J Biomed Mater Res A (2012) 100(3):768-75. doi:10.1002/jbm.a.34006

27. Campoccia D, Montanaro L, Arciola CR. A review of the biomaterials technologies for infection-resistant surfaces. Biomaterials (2013) 34(34):8533-54. doi:10.1016/j.biomaterials.2013.07.089

28. Roosjen A, Kaper HJ, van der Mei HC, Norde W, Busscher HJ. Inhibition of adhesion of yeasts and bacteria by poly(ethylene oxide)-brushes on glass in a parallel plate flow chamber. Microbiology (2003) 149(Pt 11):3239-46. doi:10.1099/mic.0.26519-0

29. Schaer TP, Stewart S, Hsu BB, Klibanov AM. Hydrophobic polycationic coatings that inhibit biofilms and support bone healing during infection. Biomaterials (2012) 33(5):1245-54. doi:10.1016/j.biomaterials.2011.10.038 
30. Huang Q, Yu HJ, Liu GD, Huang XK, Zhang LY, Zhou YG, et al. Comparison of the effects of human $\beta$-defensin 3, vancomycin, and clindamycin on Staphylococcus aureus biofilm formation. Orthopedics (2012) 35(1):e53-60. doi:10.3928/01477447-20111122-11

31. Zhu C, Tan H, Cheng T, Shen H, Shao J, Guo Y, et al. Human $\beta$-defensin 3 inhibits antibiotic-resistant Staphylococcus biofilm formation. J Surg Res (2013) 183(1):204-13. doi:10.1016/j.jss.2012.11.048

32. Nablo BJ, Prichard HL, Butler RD, Klitzman B, Schoenfisch MH. Inhibition of implant-associated infections via nitric oxide release. Biomaterials (2005) 26(34):6984-90. doi:10.1016/j.biomaterials.2005.05.017

33. Wang J, Zhu Y, Bawa HK, Ng G, Wu Y, Libera M, et al. Oxygen-generating nanofiber cell scaffolds with antimicrobial properties. ACS Appl Mater Interfaces (2011) 3(1):67-73. doi:10.1021/am100862h

34. Romanò CL, Toscano M, Romanò D, Drago L. Antibiofilm agents and implant-related infections in orthopaedics: where are we? J Chemother (2013) 25(2):67-80. doi:10.1179/1973947812Y.0000000045

35. Hansen EN, Zmistowski B, Parvizi J. Periprosthetic joint infection: what is on the horizon? Int J Artif Organs (2012) 35(10):935-50. doi:10.5301/ijao.5000145

36. Shinefield H, Black S, Fattom A, Horwith G, Rasgon S, Ordonez J, et al. Use of a Staphylococcus aureus conjugate vaccine in patients receiving hemodialysis. $N$ Engl J Med (2002) 346(7):491-6. doi:10.1056/NEJMoa011297

37. Brady RA, O’May GA, Leid JG, Prior ML, Costerton JW, Shirtliff ME. Resolution of Staphylococcus aureus biofilm infection using vaccination and antibiotic treatment. Infect Immun (2011) 79(4):1797-803. doi:10.1128/IAI.00451-10

38. Yilmaz C, Colak M, Yilmaz BC, Ersoz G, Kutateladze M, Gozlugol M. Bacteriophage therapy in implant-related infections: an experimental study. J Bone Joint Surg Am (2013) 95(2):117-25. doi:10.2106/JBJS.K.01135

39. Ntrouka VI, Slot DE, Louropoulou A, Van der Weijden F. The effect of chemotherapeutic agents on contaminated titanium surfaces: a systematic review. Clin Oral Implants Res (2011) 22(7):681-90. doi:10.1111/j.1600-0501. 2010.02037.x

40. Ercan B, Kummer KM, Tarquinio KM, Webster TJ. Decreased Staphylococcus aureus biofilm growth on anodized nanotubular titanium and the effect of electrical stimulation. Acta Biomater (2011) 7(7):3003-12. doi:10.1016/j.actbio. 2011.04.002

41. Del PozoJL, Rouse MS, Euba G, Kang CI, Mandrekar JN, Steckelberg JM, et al. The electricidal effect is active in an experimental model of Staphylococcus epidermidis chronic foreign body osteomyelitis. Antimicrob Agents Chemother (2009) 53(10):4064-8. doi:10.1128/AAC.00432-09

42. van der Borden AJ, van der Mei HC, Busscher HJ. Electric block current induced detachment from surgical stainless steel and decreased viability of Staphylococcus epidermidis. Biomaterials (2005) 26(33):6731-5. doi:10.1016/j.biomaterials. 2004.04.052

43. Pickering SA, Bayston R, Scammell BE. Electromagnetic augmentation of antibiotic efficacy in infection of orthopaedic implants. J Bone Joint Surg Br (2003) 85(4):588-93. doi:10.1302/0301-620X.85B4.12644

44. Kizhner V, Krespi YP, Hall-Stoodley L, Stoodley P. Laser-generated shockwave for clearing medical device biofilms. Photomed Laser Surg (2011) 29(4):277-82. doi: $10.1089 /$ pho. 2010.2788

Conflict of Interest Statement: The authors declare that the research was conducted in the absence of any commercial or financial relationships that could be construed as a potential conflict of interest.

Received: 09 May 2014; accepted: 29 July 2014; published online: 15 August 2014.

Citation: Connaughton A, Childs A, Dylewski S and Sabesan VJ (2014) Biofilm disrupting technology for orthopedic implants: what's on the horizon? Front. Med. 1:22. doi: $10.3389 /$ fmed.2014.00022

This article was submitted to Infectious Diseases, a section of the journal Frontiers in Medicine.

Copyright $(2014$ Connaughton, Childs, Dylewski and Sabesan. This is an open-access article distributed under the terms of the Creative Commons Attribution License (CC BY). The use, distribution or reproduction in other forums is permitted, provided the original author(s) or licensor are credited and that the original publication in this journal is cited, in accordance with accepted academic practice. No use, distribution or reproduction is permitted which does not comply with these terms. 